Acta Technologica Agriculturae 2

Nitra, Slovaca Universitas Agriculturae Nitriae, 2015, pp. 42-45

\title{
APPLICATION OF CLUSTERING METHOD TO DETERMINE PRODUCTION ZONES OF FIELD
}

\author{
Martin INGELI*, Jana GALAMBOŠOVÁ, Renáta BENDA PROKEINOVÁ, Vladimír RATAJ \\ Slovak University of Agriculture in Nitra, Slovak Republic
}

\begin{abstract}
Determining the production zones of field is an important analysis in the precision farming technology as these may be used to control field operations in site-specific application. The aim of this paper was to evaluate the potential to identify the yield potential zones based on historical yield maps and to evaluate the procedure over the growing extent of input data. Standardized yield values from six growing seasons were considered. Suitable datasets were created, and hierarchical and non-hierarchical clustering methods were applied to create clusters. Results showed that using the data from commercial combine monitoring systems enables determining the zones. Multiple yield data are recommended as the values of analyses increase with the increased number of input datasets. However, commercial data have limitations in terms of complexity.
\end{abstract}

Keywords: management zones, clusters, yield data, yield potential, standardization

The theory of management zones within field is discussed for a longer period of time (Fridgen, 2000). To implement the precision agriculture technology at a farm level, it is necessary to determine whether the spatial variability of fields is consistent over several growing seasons (Adamchuk, 2004). High- and low-yielding zones can be determined from yield maps. Afterwards, the cause of permanently low yield can be detected and removed by field managements. Also, the latest technology for the variable rate application of nitrogen (sensor ISARIA) is based on yield potential zones (Galambošová et al., 2015). Delin and Berglund (2005) suggested creating management zones based on risk levels for drought and water logging. Zhang et al. (2010) reported the use of zone mapping as a decision support tool for variable rate application. Rataj and Galambošová (2006) proposed to use the cluster analyses for identifying highand low-profitability zones.

The most accessible source of field variability is a yield map created during the combine harvest. As shown by Ingeli et al. (2015), yield maps are a reliable source of information when the trend in yield across the field needs to be defined.

In order to create the yield potential zones, data have to be processed by cluster analysis statistics. Based on Khosla et al. (2010), there are numerous techniques for delineating management zones. Some of them are based on single soil or crop property or a combination of several properties that are known to affect crop productivity and yield. As shown by Galambošová et al. (2014), both the hierarchical and non-hierarchical clustering methods are used when determining the management zones from yield maps. The hierarchical method allows determining the statistically significant number of clusters as well as helps to interpret the data. The Ward's method can also be used as input information before conducting the k-means clustering method. The aim of this paper is to evaluate the potential to identify the yield potential zones based on historical yield maps and to evaluate the procedure over the growing extent of input data.

\section{Material and methods}

In order to conduct the analyses, a field with sufficient historical yield data was selected at a commercial farm in Turčiansky Dur. All available data will be processed in AGROCOm MAP (Claas Agrosystems); the pre-processing of yield data will be conducted based on the methodology suggested by Ingeli et al. (2013), where the values outside the biological limit will be removed.

In order to be able to process the yield data from different seasons and of different crops, the pre-processing of these data was conducted, and standardized normal values were calculated based on the following formula:

$$
S N V=\frac{(x-\bar{x})}{S D} \times 100, \%
$$

where:

SNV - standardized normal values

$x \quad$ - actual value of parameter

$\bar{X} \quad$ - arithmetic mean

SD - standard deviation

Data will be exported to a format suitable to use in ArcGIS (ESRI), the monitoring points will be targeted across the field so that each monitoring point covers an equal area. Data for each monitoring point will be selected, and the basic dataset will be created. 
For the purpose of this paper, the data will be grouped into three datasets with a different number of yield datasets (datasets from different years), and the clustering procedure will be applied.

The methodology suggested by Galambošová et al. (2014) will be used, with the hierarchical clustering procedure in the first step to identify the number of clusters and with the non-hierarchical procedure in the second step to identify the members of each cluster and its characteristics. For this purpose, the statistical software SAS and STATISTICA will be used.

\section{Results and discussion}

In the first step, the yield data for the selected field were targeted. The historical yield maps were obtained for the following years: 2004 growing spring barley, 2005 growing winter wheat, 2006 growing spring barley, 2007 growing spring oilseed rape, 2008 growing winter wheat, and 2010 growing spring barley. As this analysis uses yield data as an indicator of field variability, datasets from the years where variable application was conducted were removed from analysis. The yield data were standardized, and values for the designed monitoring points were selected in ArcGIS. The original network consisted of 67 monitoring points. Due to the availability of yield monitoring data from combine harvesters, values for the number of monitoring points are missing in some seasons. Data were pre-processed, so the identification of yield at selected monitoring points

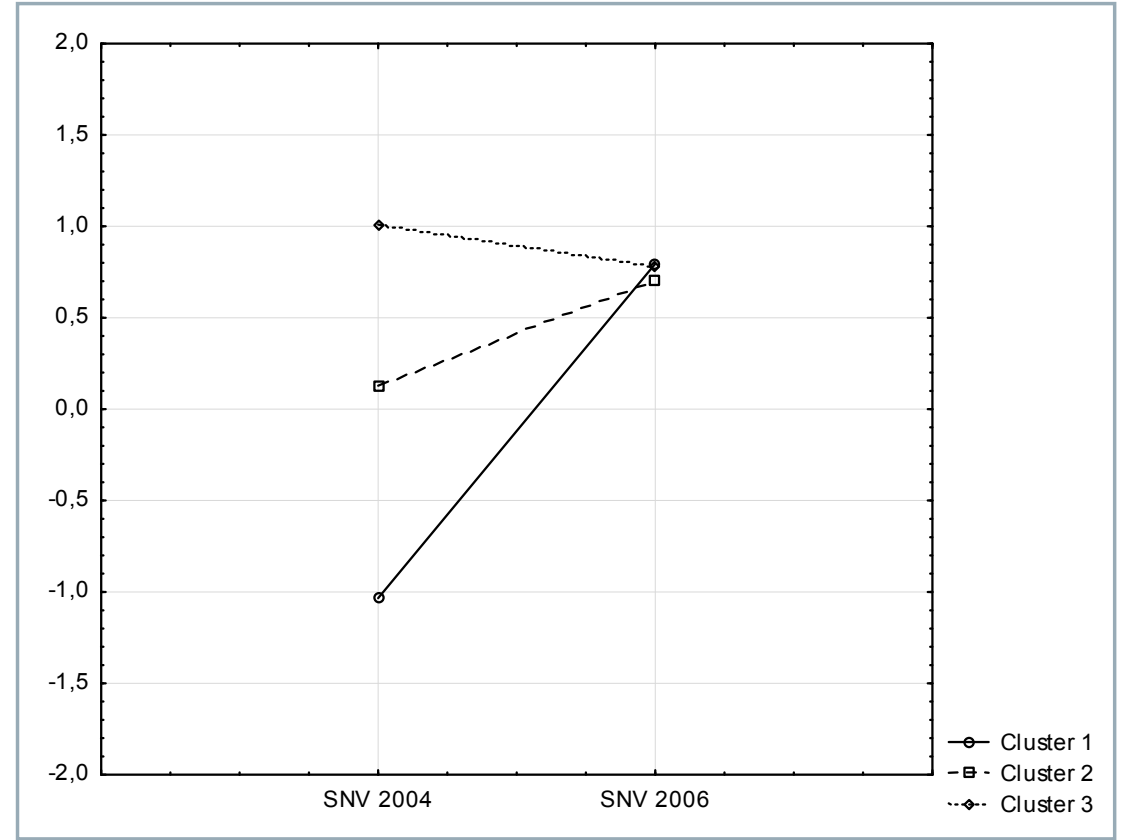

Figure 1 Means for clusters created from dataset 1

showed some limitations of these data. In some years, this might be however overcome by interpolation of raw data (Oliver et al., 2010).

The basic statistics of the standardized yield data is given in Table 1. The three datasets were created from the available data where the combination of 2, 3 and 4 historical yield data was used, as shown in Table 1.

The most variable yield was obtained in year 2004, with the variation coefficient of $28 \%$. Yield was more uniform in the other analysed years, with the coefficient of variability up to $14 \%$. The hierarchical cluster analyses were applied to the three datasets and results were analysed. The Ward's method did not show any relevant number of clusters; therefore, the centroid method was applied. Here, the CCC criterion showed that the most suitable number of clusters is three. Afterwards, the clustering process by $k$-means analyses used three clusters as pre-set up.

The results of k-means clustering are shown in Figures 1-3. ANOVA was conducted for each procedure.

Results showed that using the dataset 1, where yield data from two years growing spring barley, did not show clusters that would be different in terms of yield potentials. This is due to the fact that the yield in 2006 showed very little variability. Based on the ANOVA of the clusters, SNV 2006 did not show a significant effect on the clusters $(p<0.05)$.

Table 1 Basic statistics of input standardized yield data and identification of tested datasets

\begin{tabular}{|c|c|c|c|c|}
\hline $\begin{array}{ll} & \text { Year } \\
\text { Parameter } & \end{array}$ & $\begin{array}{c}2004 \\
\text { Spring barley }\end{array}$ & $\begin{array}{c}2006 \\
\text { Spring barley }\end{array}$ & $\begin{array}{l}2007 \\
\text { Oilseed rape (spring) }\end{array}$ & $\begin{array}{c}2010 \\
\text { Spring barley }\end{array}$ \\
\hline Mean & 0.03 & 0.09 & 0.13 & -0.06 \\
\hline Standard deviation & 0.84 & 0.63 & 0.95 & 0.84 \\
\hline Minimum & -3.13 & -1.48 & -1.46 & -2.78 \\
\hline Maximum & 1.82 & 1.69 & 2.19 & 0.99 \\
\hline Coefficient of variability & $28 \%$ & $7 \%$ & $7.3 \%$ & $14 \%$ \\
\hline Number of records & 63 & 66 & 61 & 39 \\
\hline \multirow{3}{*}{ DATASETS } & \multicolumn{2}{|c|}{ DATASET 1} & & \\
\hline & \multicolumn{3}{|c|}{ DATASET 2} & \\
\hline & \multicolumn{4}{|c|}{ DATASET 3} \\
\hline
\end{tabular}




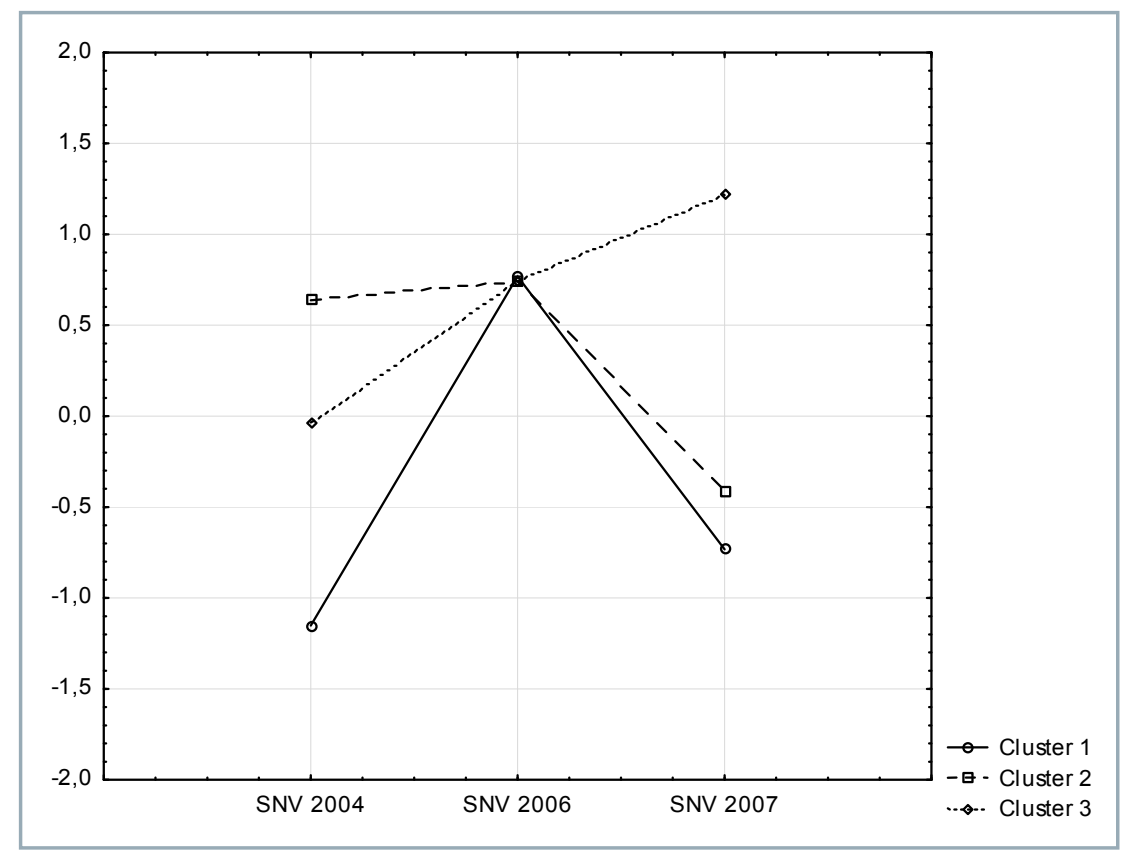

Figure 2 Means for clusters created from dataset 2

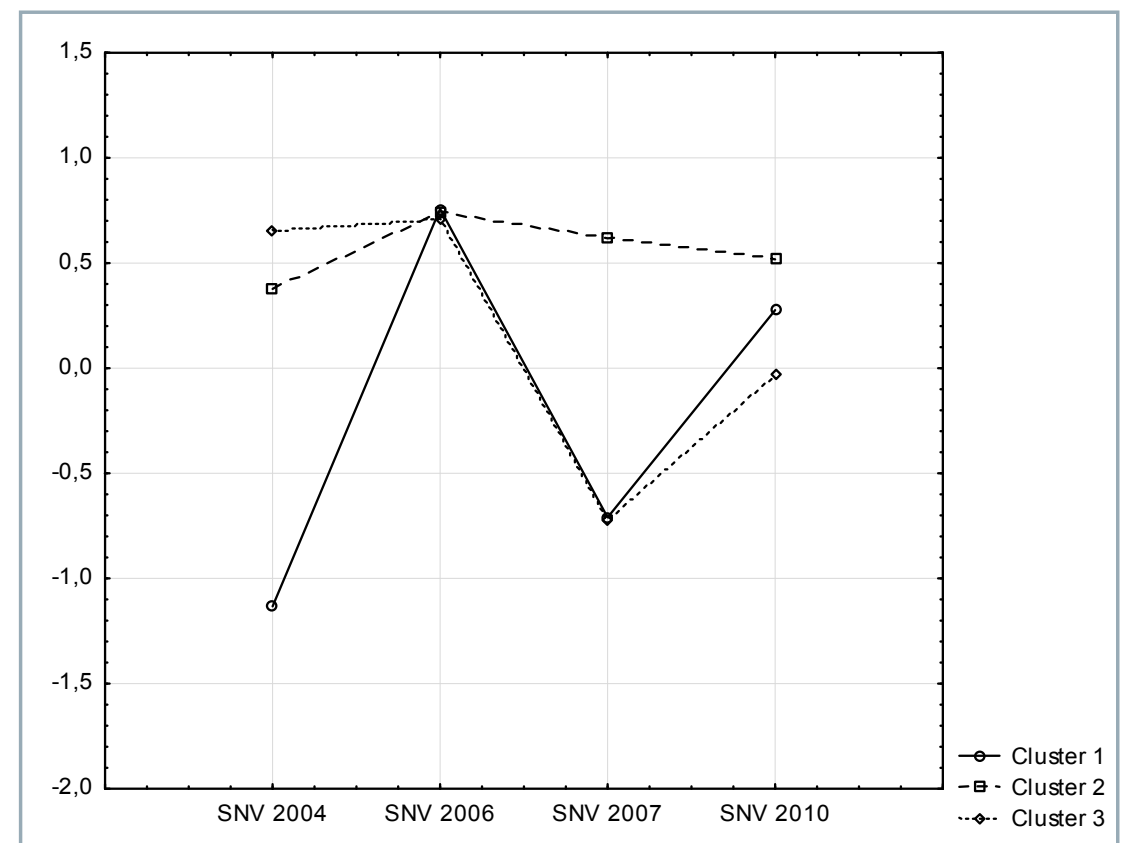

Figure 3 Means for clusters created from dataset 3
When including the data from 2007 (significant at $p<0.05$ ), the clustering procedure identified the low-yielding zones (cluster 1) in Figure 2. Cluster 2 reached above-average yields in 2004, but below-average yield in 2007, cluster 3 performed in other way round. Using the dataset 3, which included SNV 2010 (significant at $p<0.05$ ), the monitoring points are clustered so that cluster 2 appears as the high-yielding zone of the field, which yielded across the years always above the average. The other two clusters have variable yielding potential, but when the nonsignificant yield data from 2006 are excluded, cluster 2 is characterized as the low-yielding zone (always below the average yield). In this case, the input dataset was reduced to 39 monitoring points due to lack of data in the bottom part of the field in 2010. Differences and overlaps in clusters in terms of cluster members are obvious from Tables 2-4.

Increasing the number of yield maps included into the analyses, the more distinct zones are determined. For the practical use of these results, it would be recommended to include the weather data into the procedure and soil verifications. This was also suggested by Flemming and Westfall (2000), King et al. (2005) and Li et al. (2008).

\section{Conclusion}

Determining the yield potential within field zones is an important analysis conducted in precision farming. Historical yield data appear to be the most accessible data. Results showed that using the data from commercial combine monitoring systems enables determining the zones based on the similarity of monitoring points when assessing the yield in particular years. However, the values of the analyses

Table 2 Cluster members when using dataset 1

\begin{tabular}{|l||c|c|c|c|c|c|c|c|c|c|c|c|c|c|c|c|c|c|c|c|c|c|c|c|c|}
\hline Cluster 1 & 5 & 9 & 11 & 16 & 19 & 30 & 32 & 35 & 38 & 39 & 40 & 41 & 47 & & & & & & & & & & & & \\
\hline Cluster 2 & 1 & 2 & 3 & 7 & 8 & 14 & 17 & 18 & 20 & 22 & 23 & 24 & 28 & 29 & 34 & 37 & 43 & 44 & 45 & 48 & 49 & 50 & 51 & 52 & 53 \\
\hline Cluster 3 & 4 & 6 & 10 & 12 & 13 & 15 & 21 & 25 & 26 & 27 & 31 & 33 & 36 & 42 & 46 & & & & & & & & & \\
\hline
\end{tabular}

Table 3 Cluster members when using dataset 2

\begin{tabular}{|c|c|c|c|c|c|c|c|c|c|c|c|c|c|c|c|c|c|c|c|c|c|c|c|c|c|}
\hline Cluster 1 & 5 & 7 & 9 & 19 & 30 & 32 & 38 & 39 & 41 & & & & & & & & & & & & & & & & \\
\hline Cluster 2 & 3 & 4 & 6 & 8 & 10 & 13 & 14 & 18 & 21 & 24 & 25 & 26 & 27 & 28 & 31 & 33 & 34 & 37 & 42 & 43 & 44 & 45 & 46 & 52 & 53 \\
\hline Cluster 3 & 1 & 2 & 11 & 12 & 15 & 16 & 17 & 20 & 22 & 23 & 29 & 35 & 36 & 40 & 47 & 48 & 49 & 50 & 51 & & & & & & \\
\hline
\end{tabular}


Table 4 Cluster members when using dataset 3

\begin{tabular}{|l||l|l|l|l|l|l|l|l|l|l|}
\hline Cluster 1 & 3 & 5 & 10 & 17 & 19 & 23 & 24 & 25 & \\
\hline Cluster 2 & 1 & 6 & 8 & 11 & 12 & 20 & 21 & 26 & 28 & 29 \\
\hline Cluster 3 & 2 & 4 & 7 & 9 & 13 & 14 & 15 & 16 & 18 & 22 \\
\hline
\end{tabular}

increase with the increased number of input datasets. Therefore, multiple yield data are recommended to use despite the fact that commercial tdata have limitations in terms of complexity.

\section{Acknowledgement}

This paper was prepared in the frame of the research project ITMS 26220220014 funded from the European Union - ITEPAg: Application of information technologies to increase the environmental and economic efficiency of the production agro-system. This work was co-funded by the European Community under the project no. ITMS 26220220180: Building the Research Centre 'AgroBioTech'.

\section{References}

ADAMCHUK, V. et al. 2004. EC04-704 Precision agriculture: Listening to the story told by yield maps. Historical materials from University of Nebraska - Lincoln Extension. Paper 710. Available at http:// digitalcommons.unl.edu/

DELIN, S. - BERGLUND, K. 2005. Management zones classified with respect to drought and waterlogging. In Precision Agriculture, 2005, no. 6, pp. 321-340.

FLEMMING, K. L. - WESTFALL, D. G. - WIENS, D. W. - BRODAHL, M. C. 2000. Evaluating farmer defined management zone maps for variable rate fertilizer application. In Precision Agriculture, 2000, no. 2, pp. 201-215.

FRIDGEN, J. J. 2000. Delineation and analysis of site-specific management zones. In Conference on Geospatial Information in Agriculture and Forestry, Lake Buena Vista, Florida, 10-12 January, 2000.

GALAMBOŠOVÁ, J. - INGELI, M. - RATAJ, V. 2015. Field evaluation of variable application of nitrogen using the information on crop in combination with information on yield potential zone of the field. In Agrochémia, vol. 19 (55), 2015, no. 2, pp. 18-21. ISSN 1335-2415. GALAMBOŠOVÁ, J. - RATAJ, V. - PROKEINOVÁ, R. - PREŠINSKÁ, J. 2014. Determining the management zones with hierarchic and non-hierarchic clustering methods. In Research in Agricultural Engineering, 2014, no. 60, pp. S44-S51.

INGELI, M. - RATAJ, V. - GALAMBOŠOVÁ, J. - MACÁK, M. 2015. Study on correlation of data from yield monitoring system and hand samples. In Acta Technologica Agriculturae, vol. 18, 2015, no. 1, pp. 10-13.

INGELI, M. - RATAJ, V. - GALAMBOŠOVÁ, J. - MACÁK, M. MESÁROŠ, L. 2013. Processing and interpretation of datas obtained from yield monitoring system. In Trends in Agricultural Engineering 2013. Prague : Czech University of Life Sciences Prague, 2013, pp. 277-281.

KHOSLA, R. - WESTFALL, D. G. - REICH, R. M. - MAHAL, J. S. - GANGLOFF, W. J. 2010. Spatial variation and site-specific management zones. In Oliver M. 2010. Geostatistical Applications for Precision Agriculture. London : Springer, 2010.

KING, J. A. - DAMPNEY, P. M. R. - LARK, R. M. - WHEELER, H. C. - BRADLEY, R. I. - MAYR, T. R. 2005. Mapping potential crop management zones within fields: Use of yield-map series and patterns of soil physical properties identified by electromagnetic induction sensing. In Precision Agriculture, 2005, no. 6, pp. 167-181. LI, Y. - SHI, Z. - WU, CH. - LI, H. - LI, F. 2008. Determination of potential management zones from soil electrical conductivity, yield and crop data. In Journal of Zhejiang University SCIENCE B, vol. 9, 2008, no. 1, pp. 68-76.

OLIVER, M. et al. 2010. Geostatistical Applications for Precision Agriculture. Springer, 2010.

RATAJ, V. - GALAMBOŠOVÁ, J. 2006. Farm production planning based on 4-years site-specific information. In: Agricultural Engineering for a Better World : XVI CIGR World Congress, September 3-7, 2006. Bonn, Düsseldorf : VDI Verlag GmbH, 2006, pp. 375-376.

ZHANG, X. et al. 2010. Zone mapping application for precisionfarming: A decision support tool for variable rate application. In Precision Agriculture, 2010, no. 11, pp. 103-114. 